\title{
The Effect of Electrode Configuration on the Unipolar His-Bundle Electrogram
}

\author{
ALAN H. KADISH, FRED MORADY, SHIMON ROSENHECK, JONI SUMMITT, \\ and STEVE SCHMALTZ
}

From the Division of Cardiology and the Clinical Research Center, Department of Internal Medicine, University of Michigan Medical Center, Ann Arbor, Michigan

\begin{abstract}
KADISH, A.H., ET AL.: The Effect of Electrode Configuration on the Unipolar His-Bundle Electrogram. Although "unipolar electrograms" recorded from the His-bundle position have been used to help position catheters for His-bundle ablation, the techniques used to record such electrograms have not been standardized. The effects of five anode locations (right chest wall, anterior chest wall, left chest wall, posterior chest wall, and inferior vena cava) on unipolar atrial, His bundle and ventricular electrograms recorded from the His-bundle position were examined in ten patients undergoing clinical electrophysiology studies. Electrograms were recorded at filter settings of 50-500 as well as $0.05-1000 \mathrm{~Hz}$. The location of the anode had no consistent effect on the amplitude, duration or morphology of any of the electrograms at either filter setting, but signals recorded with the inferior vena cava anode had the highest signal-to-noise ratio. A filter setting of $50-500 \mathrm{~Hz}$ decreased the amplitude of atrial $(0.72$ to $0.33 \mathrm{mV}-\mathrm{P}<0.01)$, His bundle ( $0.38 \mathrm{vs} 0.32$ $\mathrm{mV}-\mathrm{P}<0.01)$ and ventricular electrograms (3.71 vs $2.01 \mathrm{mV}-\mathrm{P}<0.001)$ compared to a filter setting of $0.05-1,000 \mathrm{~Hz}$. The filter setting did not affect electrogram duration. We concluded that the use of an electrode catheter in the inferior vena cava as the anode when recording "unipolar electrograms" from the His-bundle position yields a better signal-to-noise ratio than a skin patch on the chest and appears to be the optimal method for recording unipolar electrograms. (PACE, Vol. 12, September 1989)
\end{abstract}

His bundle, unipolar, filtering, electrograms

\section{Introduction}

His-bundle electrograms were first recorded in man in $1969 .{ }^{1}$ In recent years, precise localization of the His deflection has gained importance with the advent of catheter ablation of the atrioventricular (AV) junction. ${ }^{2-4}$ "Unipolar" recordings have been suggested at the optimal method by which to localize the His bundle for ablation. ${ }^{5}$ Evans et al. have reported that the probability of successful catheter ablation of the AV junction is related to the amplitude of the His-bundle elec-

Supported in part by Grants 5MO1-RRo0042-25 and HL 40667-1 from the National Institute of Health, Bethesda, Maryland.

Address for reprints: Alan H. Kadish, M.D., University of Michigan Hospital, 1500 E. Medical Center Drive, Cardiology, B1-F245-0022, Ann Arbor, MI 48109.

Received March 17, 1989; revision May 24, 1989; accepted June 5, 1989. trogram recorded at the shock site ${ }^{6}$ However, most recordings made in the clinical electrophysiology laboratory are not truly unipolar in that an anode is located somewhere in the extracardiac space. The location of this electrode could potentially affect the amplitude of electrograms recorded from the His-bundle position since in fact a wide bipolar electrogram is being recorded. Therefore, this study was undertaken to examine the effects of the position of the anode on the amplitude and duration of electrograms recorded from the His position.

\section{Methods}

\section{Patient Population}

Ten patients undergoing a clinically indicated electrophysiology study were the subjects of this article. Thirteen patients were initially evaluated for the study, but three had marked 
Table I.

Clinical Characteristics of Subjects

$\begin{array}{ll}\text { Age } & \\ 50 \pm 4 \text { years } & \\ \text { Sex } & \\ 6 \text { Male } & \\ 4 \text { Female } & 7 \\ \text { Heart Disease } & 1 \\ \text { Coronary artery disease } & 2 \\ \text { Cardiomyopathy } & \\ \text { None } & 5 \\ \text { Referring Dx } & 3 \\ \text { ventricular tachycardia } & 1 \\ \text { syncope } & 1 \\ \text { palpitations } & \\ \text { bradycardia } & \\ \text { HV Interval } 50 \pm 3 \text { msec }(>55 \text { msec in 2 patients) } & \\ \end{array}$

beat-to-beat variability in His amplitude using unipolar or bipolar recording techniques and were excluded. Eight patients had heart disease and two did not. Characteristics of the study population are shown in Table I.

\section{Study Protocol}

Studies were performed in the fasting and unsedated state. Two or three quadripolar catheters were inserted through the femoral vein and advanced to the heart as required for the clinical study. Blood pressure was monitored through a 5 Fr sheath in the femoral artery as clinically indicated.

One $6 \mathrm{Fr}$ quadripolar catheter with a $1-\mathrm{cm}$ interelectrode distance (USCI, USCI, Billerica, MA, USA) was placed in the His-bundle position in the standard fashion. Electrograms were recorded before any attempt at tachycardia induction, to minimize the effects of catecholamine release. Bipolar electrograms were recorded in a routine fashion at filter settings of $50-500 \mathrm{~Hz}$ from poles 1 and 2, 2 and 3, and 3 and 4 of the catheter. The largest bipolar His deflection was identified and the proximal pole of this bipolar pair was used for unipolar recordings.

Unipolar electrograms were recorded on a Siemens Mingograf 7 (Siemens-Elema, Solona, Sweden) at a paper speed of $100 \mathrm{~mm} / \mathrm{sec}$. In each case the electrode catheter in the His-bundle position was used as the cathode. Recordings were made at filter settings of both $0.05-1000 \mathrm{~Hz}$ and $50-500 \mathrm{~Hz}$. Electrograms at filter settings of $50-500 \mathrm{~Hz}$ were recorded at a gain of $20-40$ $\mathrm{mm} / \mathrm{mV}$ while electrograms at filter settings of $0.05-1,000 \mathrm{~Hz}$ were recorded at gains of both $20-40 \mathrm{~mm} / \mathrm{mV}$ and $10 \mathrm{~mm} / \mathrm{mV}$ to allow measurement of the higher amplitude ventricular electrograms. Five locations were used for the anode: four on the chest wall at the level of the fifth intercostal space (right lateral, center, left lateral, center back) and one in the inferior vena cava at approximately the level of the renal veins. The indifferent electrodes located on the chest wall or leg were silver, silver/chloride electrodes with an active area of $12 \mathrm{~mm}$ and a total size of 20 $\mathrm{mm}$. The cable consisted of shielded copper wire. The skin was abraded with guaze and electrode gel was used at the electrode-skin interface. The inferior vena cava electrode was the distal pole of a 6 Fr USCI Quadripolar catheter. Parameters measured at each filter setting for each anode location included peak-to-peak electrogram amplitude and electrogram duration. Measurements of the atrial, His, and ventricular electrograms were made manually. Electrogram durations were measured to the nearest $5 \mathrm{msec}$ at a fixed gain of $40 \mathrm{~mm} / \mathrm{mV}$. Atrial and His-bundle electrograms were measured to the nearest $0.05 \mathrm{mV}$ and ventricular electrograms to the nearest $1 \mathrm{mV}$. Five consecutive sinus beats were averaged and the mean value used for data analysis.

\section{Data Analysis}

Data are expressed as Mean \pm Standard Error. The effect of patch location, filtering, and their interaction was analyzed using a repeated measures analysis of variance. Multiple comparisons were performed using Fisher's least significant difference procedure. To examine variability in electrogram measurements within individual patients, a coefficient of variation was calculated for the five measurements made in each patient. A P value of $<0.05$ was considered significant.

\section{Results}

The mean bipolar electrogram amplitude was $0.52 \pm 0.04,0.35 \pm 0.04$, and $2.86 \pm 0.18 \mathrm{mV}$ for the atrial, His, and ventricular electrograms, respectively. The mean durations of these electrograms 
A
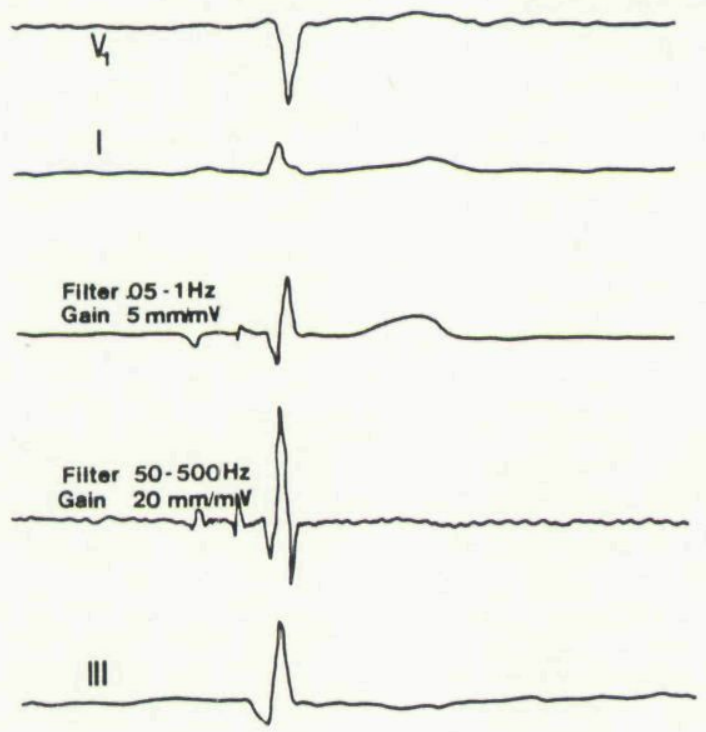

B
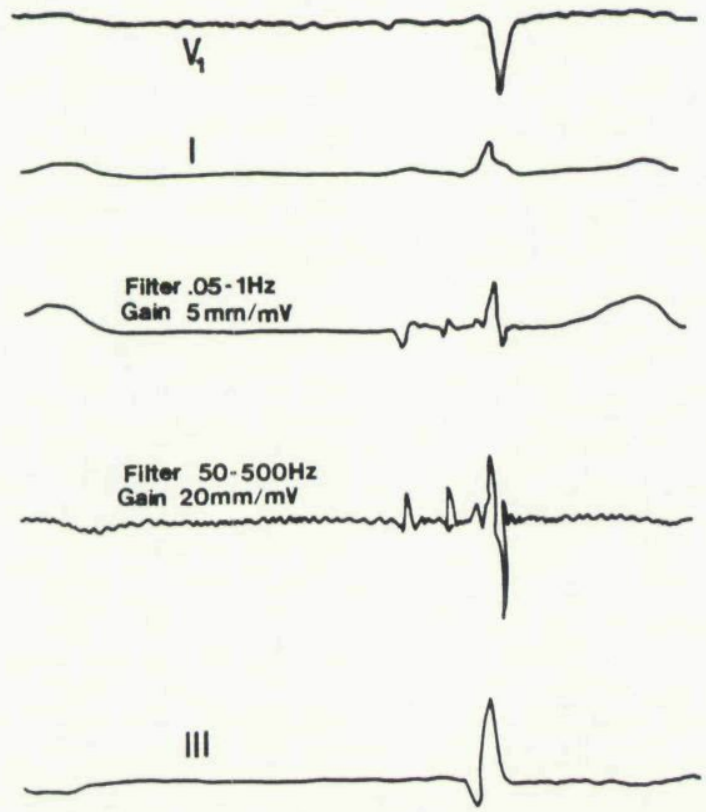

C
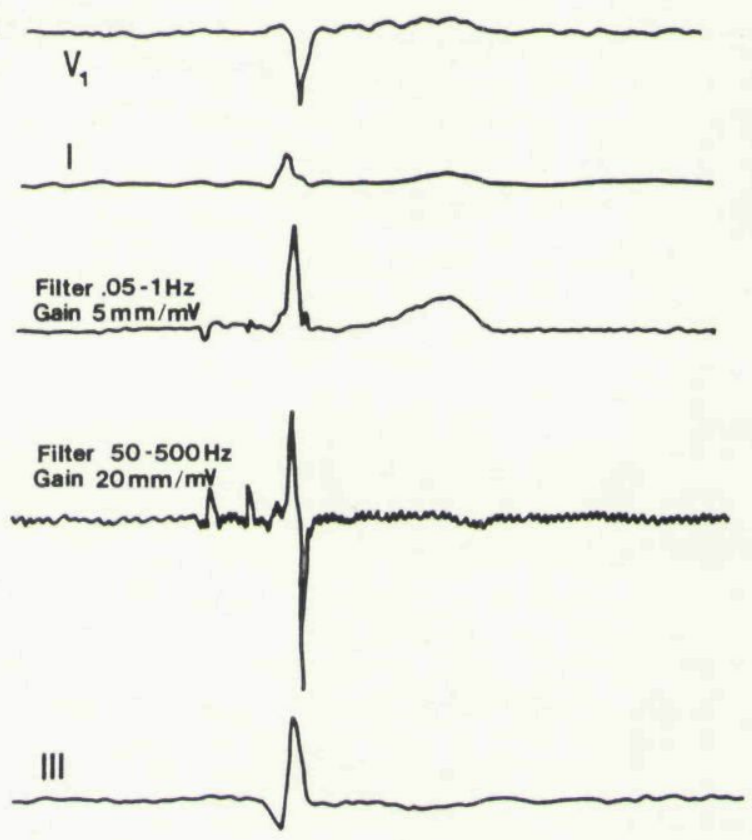

D
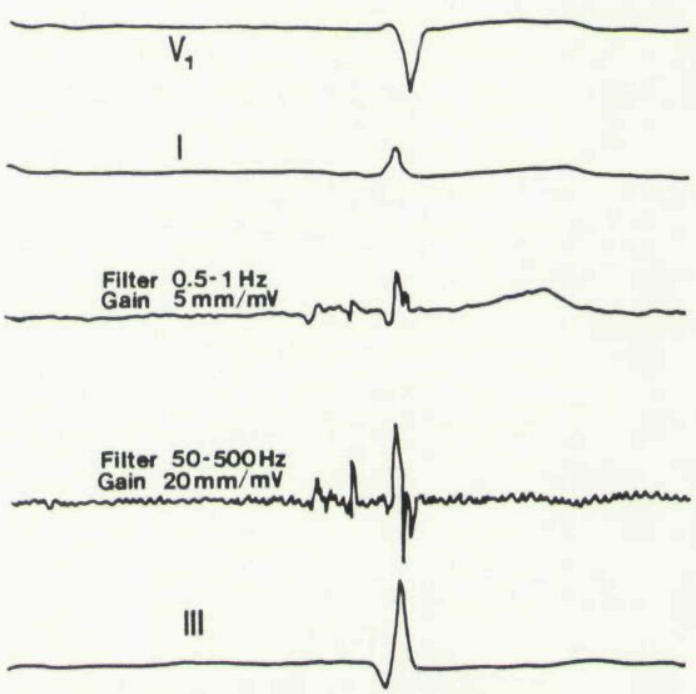

Figure 1. Electrocardiogram and unipolar electrogram tracings recorded from the His-bundle position. Panels $A-D$ are recordings made with the anode located on the right chest (panel A), anterior chest (B), left chest (C) and posterior (D) chest wall at the level of the fifth intercostal space. Panel E shows recordings obtained with an electrode catheter in the inferior vena cava serving as the anode. Each panel is similarly organized with EKG leads $V_{1}$, I, His-bundle electrogram with filter settings of $0.05 \mathrm{~Hz}-1 \mathrm{kHz}$, His-bundle electrogram with filter settings of $50-500 \mathrm{~Hz}$ and EKG lead III shown from top to bottom. There were no significant differences in electrogram amplitude or morphology between the various anode locations. The IVC electrode recording has the highest signal to noise ratio as is evident in the recording made with a $20 \mathrm{~mm} / \mathrm{m} \mathrm{V}$ gain. 
$\mathbf{E}$
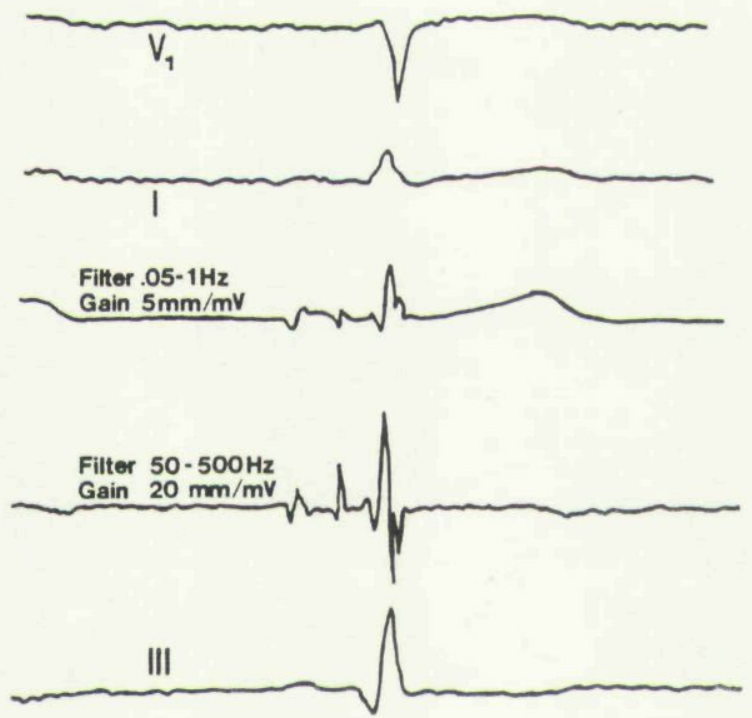

Figure 1. Continued

were $54.1 \pm 1.6,16.7 \pm 0.4$, and $95.1 \pm 2.0 \mathrm{msec}$, respectively.

\section{Effect of Anode Location on Electrograms}

Figure 1 shows examples of electrograms recorded with each of the two filter settings utilizing each of the five anode locations. There is a small amount of beat-to-beat variability in the amplitudes of the various components of the electrograms. However, there were no major dif- ferences in electrogram amplitude, duration or morphology between the various anode locations.

Table II summarizes data on electrogram amplitudes. Data from each filter setting and pooled data from both settings are shown. There were no significant differences in electrogram amplitude between the various anode locations. In addition, there was no interaction between the effect of filter setting and anode location on electrogram amplitudes. Although there was no systematic effect of anode location on electrogram amplitudes, small differences were observed between different locations in individual patients. The mean coefficient of variation was $15 \%$ for atrial amplitude, $17 \%$ for His bundle electrogram amplitude, and $16 \%$ for ventricular amplitude.

Table III summarizes data on electrogram durations. Once again, anode location had no effect on electrogram characteristics and there was no interaction between filter settings and anode location on electrogram duration. The use of an electrode catheter in the inferior vena cava as the anode was consistently associated with the lowest noise level, as shown in Figure 1.

\section{Effect of Filtering on Electrogram Characteristics}

The use of filter settings of $50-500 \mathrm{~Hz}$ decreased the amplitude of all electrogram components. Mean atrial electrogram amplitude was $0.72 \mathrm{mV}$ with $0.05-1,000 \mathrm{~Hz}$ filtering and $0.33 \mathrm{mV}$

Table II.

Electrogram Amplitudes (mV)

\begin{tabular}{|c|c|c|c|c|c|c|}
\hline \multirow[b]{2}{*}{ Electrogram } & \multirow[b]{2}{*}{ Filtering } & \multicolumn{5}{|c|}{ Anode Location } \\
\hline & & $\begin{array}{l}\text { Right } \\
\text { Chest }\end{array}$ & $\begin{array}{c}\text { Anterior } \\
\text { Chest }\end{array}$ & $\begin{array}{l}\text { Left } \\
\text { Chest }\end{array}$ & $\begin{array}{c}\text { Posterior } \\
\text { Chest }\end{array}$ & $\begin{array}{c}\text { Inferior } \\
\text { Vena Cava }\end{array}$ \\
\hline \multirow[t]{3}{*}{ Atrial } & $50-500 \mathrm{~Hz}$ & $0.32 \pm 0.07$ & $0.29 \pm 0.05$ & $0.28 \pm 0.04$ & $0.37 \pm 0.09$ & $0.38 \pm 0.10$ \\
\hline & $0.05-1000 \mathrm{~Hz}$ & $0.70 \pm 0.14$ & $0.73 \pm 0.18$ & $0.69 \pm 0.14$ & $0.81 \pm 0.20$ & $0.67 \pm 0.14$ \\
\hline & Total & $0.51 \pm 0.09$ & $0.51 \pm 0.10$ & $0.48 \pm 0.09$ & $0.59 \pm 0.12$ & $0.52 \pm 0.09$ \\
\hline \multirow[t]{3}{*}{ His } & $50-500 \mathrm{~Hz}$ & $0.33 \pm 0.14$ & $0.29 \pm 0.05$ & $0.32 \pm 0.12$ & $0.32 \pm 0.12$ & $0.31 \pm 0.12$ \\
\hline & $0.05-1000 \mathrm{~Hz}$ & $0.41 \pm 0.14$ & $0.38 \pm 0.14$ & $0.38 \pm 0.12$ & $0.38 \pm 0.12$ & $0.35 \pm 0.13$ \\
\hline & Total & $0.37 \pm 0.10$ & $0.35 \pm 0.09$ & $0.35 \pm 0.08$ & $0.35 \pm 0.08$ & $0.33 \pm 0.09$ \\
\hline \multirow[t]{3}{*}{ Ventricular } & $50-500 \mathrm{~Hz}$ & $2.21 \pm 0.46$ & $1.88 \pm 0.33$ & $2.04 \pm 0.34$ & $1.88 \pm 0.36$ & $2.01 \pm 0.37$ \\
\hline & $0.05-1000 \mathrm{~Hz}$ & $3.74 \pm 0.68$ & $3.63 \pm 0.69$ & $3.68 \pm 0.62$ & $3.60 \pm 0.59$ & $3.87 \pm 0.59$ \\
\hline & Total & $2.98 \pm 0.43$ & $2.76 \pm 0.42$ & $2.86 \pm 0.39$ & $2.74 \pm 0.39$ & $2.99 \pm 0.41$ \\
\hline
\end{tabular}


Table III.

Electrogram Duration (msec)

\begin{tabular}{lllcccc}
\hline & & \multicolumn{3}{c}{ Anode Location } \\
\cline { 3 - 6 } Electrogram & \multicolumn{1}{c}{ Filtering } & $\begin{array}{c}\text { Right } \\
\text { Chest }\end{array}$ & $\begin{array}{c}\text { Anterior } \\
\text { Chest }\end{array}$ & $\begin{array}{c}\text { Left } \\
\text { Chest }\end{array}$ & $\begin{array}{c}\text { Posterior } \\
\text { Chest }\end{array}$ & $\begin{array}{c}\text { Inferior } \\
\text { Vena Cava }\end{array}$ \\
\hline \multirow{2}{*}{ Atrial } & $50-500 \mathrm{~Hz}$ & $45 \pm 6$ & $50 \pm 6$ & $48 \pm 6$ & $48 \pm 6$ & $54 \pm 5$ \\
& $0.05-1000 \mathrm{~Hz}$ & $54 \pm 5$ & $52 \pm 6$ & $56 \pm 6$ & $56 \pm 6$ & $59 \pm 4$ \\
His & Total & $52 \pm 4$ & $53 \pm 4$ & $54 \pm 4$ & $53 \pm 4$ & $56 \pm 3$ \\
& $50-500 \mathrm{~Hz}$ & $16 \pm 2$ & $18 \pm 1$ & $17 \pm 1$ & $15 \pm 1$ & $16 \pm 1$ \\
& $0.05-1000 \mathrm{~Hz}$ & $18 \pm 2$ & $19 \pm 2$ & $17 \pm 1$ & $17 \pm 1$ & $18 \pm 1$ \\
Ventricular & Total & $16 \pm 1$ & $18 \pm 1$ & $16 \pm 1$ & $16 \pm 1$ & $16 \pm 1$ \\
& $50-500 \mathrm{~Hz}$ & $98 \pm 7$ & $94 \pm 7$ & $96 \pm 8$ & $98 \pm 7$ & $99 \pm 7$ \\
& $0.05-1000 \mathrm{~Hz}$ & $94 \pm 5$ & $90 \pm 6$ & $95 \pm 7$ & $96 \pm 6$ & $94 \pm 6$ \\
& Total & $96 \pm 4$ & $92 \pm 5$ & $95 \pm 5$ & $96 \pm 4$ & $96 \pm 5$ \\
\hline
\end{tabular}

with $50-500 \mathrm{~Hz}$ filtering $(\mathrm{P}<0.01)$. Mean His amplitude was $0.38 \mathrm{mV}$ with $0.05-1,000 \mathrm{~Hz}$ filtering and $0.32 \mathrm{mV}$ with $50-500 \mathrm{~Hz}$ filtering $(\mathrm{P}<0.01)$. Mean ventricular amplitude was also lower with $50-500 \mathrm{~Hz}$ filtering (2.01 vs $3.71 \mathrm{mV}$; $\mathrm{P}<0.001)$. No significant differences in electrogram durations were found between filter settings. Data on electrogram characteristics at the two filter settings for each of the patch locations are shown in Tables II and III. There was no interaction between the type of filtering used and the effect of the indifferent electrode on electrogram characteristics.

\section{Discussion}

The major finding of this study is that the location of the anode does not effect the amplitude of the His-bundle electrogram. Since the use of an electrode catheter in the inferior vena cava as the anode produces results similar to skin electrodes on the chest, but with a larger signal to ratio, it appears to be the optimal way to record unipolar electrograms.

\section{Techniques of Unipolar Recordings}

"Unipolar electrograms" have been used extensively in studying cardiac activation. Spach et al demonstrated that the peak negative $\mathrm{dV} / \mathrm{dT}$ of the unipolar electrogram corresponds to activation times derived from transmembrane poten- tials. ${ }^{7}$ Unipolar electrograms have often been recorded using a distant reference electrode as the anode ${ }^{7,8}$ Levine et al. have demonstrated that during the delivery of large energy shocks to ablate ventricular myocardium, current can be directed from an anode to a distant cathode. ${ }^{9}$ Thus the location of a distant cathode could potentially modulate current fields near a recording catheter and affect the characteristics of a "unipolar" recording. However, the effects of the location of the anode on unipolar electrograms previously have not been systematically evaluated. Several anode positions for recording the unipolar anode HisBundle electrogram were examined in this study. The location of the anode had no effect on unipolar electrograms recorded from the atrium, His bundle or the ventricle. The small surface area of the recording electrode and the anode as well as the relatively large distance between them may be in part responsible for this lack of effect.

A method that allows the recording of true unipolar electrograms is the use of a Wilson Central Terminal as the anodal pole, and this method should not be subject to positional variabilities. ${ }^{10}$ This technique has been incorporated into several computerized intraoperative mapping systems but has not been widely used in the clinical electrophysiology laboratory because it requires custom designed equipment. However, since no effect of anode location was found in this study, it appears that using an anode located at some dis- 
tance away in the extracardiac space adequately approximates a true unipolar recording.

\section{Effects of Filtering}

Analog filters attenuate incoming signals but have the advantage of rejecting unwanted electrical activity or noise. Josephson and Seides ${ }^{11}$ showed that filtering the His-bundle electrogram at $40-500 \mathrm{~Hz}$ produced a more clearly defined electrogram, but also reduced electrogram amplitude $^{11}$ (Figs. 2-3 in their text). As expected, we found that filtering at $50-500 \mathrm{~Hz}$ reduced the amplitude of the atrial, His, and ventricular deflections compared to filtering at $0.05-1000 \mathrm{~Hz}$. However, at neither filter setting was there a relationship between anode position and electrogram amplitude or morphology.

\section{Noise}

Filtering at $50-500 \mathrm{~Hz}$ reduced noise levels in electrogram recordings (Fig. 1). The use of a skin patch as the anode was associated with a higher

\section{References}

1. Damato AN, Lau SH, Berkowitz WD, et al. Recording of specialized conducting fibers in man using an electrode catheter technique. Circulation 1969; 39:435-447.

2. Gallagher JJ, Svenson RH, Kasell JH. Catheter technique for closed-chest ablation of the atrioventricular conduction system. N Engl J Med 1982; 306:194-200.

3. Scheinman MM, Morady F, Hess DS. Catheterinduced ablation of the atrioventricular junction to control refractory supraventricular arrhythmias. J Am Med Assoc 1982; 248:851-855.

4. Scheinman MM, Evans-Bell T, and the Executive Committee of the Percutaneous Cardiac Mapping and Ablation Registry. Catheter ablation of the atrioventricular junction: A report of the percutaneous mapping and ablation registry. Circulation 1984; 70:1024-1029.

5. Josephson ME. Catheter ablation of arrhythmias. Ann Int Med 1984; 101:234-237.

6. Evans GT, Jr, Scheinman MM, Fox G, et al. Predictors of successful His bundle ablation: A report noise level than using an electrode in the inferior vena cava, presumably because of interference at the electrode skin interface and perhaps because of myopotentials.

\section{Clinical Implications}

The amplitudes of the atrial and unipolar His-bundle electrograms are important in locating catheters for AV nodal ablation. ${ }^{11}$ Signal quality may be important since these deflections can typically be less than $1 \mathrm{mV}$ in amplitude. The results of this study indicate that an anode in the inferior vena cava is the optimal method for recording unipolar electrograms with standard electrophysiology equipment. However, if it is technically difficult to insert an IVC catheter, unipolar electrodes recorded with a skin patch provide quantitatively similar information and could be used instead. In addition, the results confirm that filter settings may have a substantial effect on electrogram amplitude and suggest that open filtering should be used when searching for the maximum atrial and His-bundle amplitudes.

of the percutaneous cardiac mapping and ablation registry. (abstract) J Am Coll Cardiol 1988; 2:17A.

7. Spach MS, Barr RC, Serwer GA. Extracellular potentials related to intracellular action potentials in the dog purkinje system. Circ Res 1972; 30:505519.

8. Spach MS, Miller WT, III, Miller-Jones E, et al. Extracellular potentials related to intracellular action potentials during impulse conduction in anisotropic canine cardiac muscle. Circ Res 1979; 45:188-204.

9. Levine JH, Spear JF, Weisman HF, et al. The cellular electrophysiologic changes induced by highenergy electrical ablation canine myocardium. Circulation 1986; 73:818-829.

10. Blanchard SM, Damiano RJ, Jr, Asano T, et al. The effects of distant cardiac electrical events on local activation in unipolar epicardial electrograms. IEEE Trans Biomed Eng 1987; BME-34:539-546.

11. Josephson ME, Seides SF. Clinical Cardiac Electrophysiology Techniques and Interpretations. Philadelphia, Lea \& Febiger, 1979, p. 8. 
This document is a scanned copy of a printed document. No warranty is given about the accuracy of the copy. Users should refer to the original published version of the material. 